\title{
Danish Nursing Home Staff's Perceived Visual Comfort and Perceived Usefulness of a Circadian Lighting System
}

\author{
Kathrine M. Schledermann \\ Department of Architecture, \\ Design and Media Technology \\ Aalborg University Copenhagen \\ Copenhagen SV, Denmark \\ kmsc@.create.aau.dk
}

\author{
Thomas Bjørner \\ Department of Architecture, \\ Design and Media Technology \\ Aalborg University Copenhagen \\ Copenhagen SV, Denmark \\ tbj@.create.aau.dk
}

\author{
Torben Skov Hansen \\ Chromaviso \\ Health promoting Lighting \\ Aarhus, Denmark \\ tsh@,chromaviso.com
}

\begin{abstract}
This study investigated how staff working at a Danish nursing home experienced, perceived, and used circadian lighting for two years after its installation. The purpose of the installed circadian lighting was to improve the staff and residents' health and comfort. The paper is based on an action research methodology that used interviews, observations, and a questionnaire to investigate 42 staff members' perceived visual comfort, satisfaction with, and perceptions of the usefulness of the circadian lighting. The findings revealed that circadian light was perceived as satisfactory by the staff and was perceived as a more adequate light for work than the existing lighting system. Being able to adjust the lighting was perceived as important by staff for maintaining visibility, setting the lighting depending on the activities, and meeting residents' needs. This paper demonstrates the value of applying mixed methods when analyzing subjective assessment of light and visual comfort. We present an alternative card sorting method for studying perceptions of a 24-hour lighting application. Finally, the study demonstrates the value of evaluating the lighting with end-users after two years in use to improve future lighting installations and to adjust the current installation.
\end{abstract}

\section{CCS CONCEPTS}

- Human-Centered Computing • HCI design and evaluation methods $\bullet$ User studies

\section{KEYWORDS}

Circadian lighting, visual comfort, perceived usefulness, action research.

Permission to make digital or hard copies of all or part of this work for personal or classroom use is granted without fee provided that copies are not made or

distributed for profit or commercial advantage and that copies bear this notice and the full citation on the first page. Copyrights for components of this work owned by others than ACM must be honored. Abstracting with credit is permitted. To copy otherwise, or republish, to post on servers or to redistribute to lists, requires prior specific permission and/or a fee. Request permissions from permissions@acm.org.

GoodIT '21, September 9-11, 2021, Roma, Italy

(C) 2021 Association for Computing Machinery.

ACM ISBN 978-1-4503-8478-0/21/09.

https://doi.org/10.1145/3462203.3475881

\section{ACM Reference format:}

Kathrine Marie Schledermann, Thomas Bjørner and Torben Skov Hansen. 2021. Danish Nursing Home Staff's Perceived Visual Comfort and Perceived Usefulness of a Circadian Lighting System. In Proceedings of ACM International Conference on Information Technology for Social Good (GoodIT '21), September 9-11, 2021, Roma, Italy. ACM, New York, NY, USA, 6 pages. https://doi.org/10.1145/3462203.3475881

\section{Introduction}

The effects of environmental quality in indoor environments and occupational spaces on human well-being and health has been of increasing interest over the last decade $[2,7,16,23]$. The growing interest in studying health-care environments, including lighting, can be explained by increased awareness of the effects that indoor environments have on staff and patients' health outcomes and psychological well-being [28]. Moreover, investments in better indoor environments and in smart welfare technologies are considered to increase quality of life and quality of care [6].

To date, studies on circadian lighting have largely focused on physiological effects and photometric measures, and they have mostly been conducted in laboratory settings, where the lighting is carefully controlled. Researchers recognize the need for field studies of well-being and health [10] in health care environments, where lighting potentially has significant effects. The number of field studies published in health care environments is growing steadily $[4,8,10,12,14,19,22,25,27]$. However, these studies do not discuss or identify the complexity of implementing lighting systems intended to stimulate circadian rhythms in real-life environments such as hospitals and elder care facilities that involve dynamic and sometimes hectic practices, as well as a wide range of functions and patients, and where the lighting is not the staff's main priority. Nor does the previous work address long-term practices (e.g., adaptation, behavior, acceptance). The changes in the lighting practices that take place over the period of use can be valuable for informing the design of future lighting installations.

Therefore, this study is aimed at shedding light on 1) staff's experiences with working in a circadian-lit environment, 2) the use of the lighting in every practice during various times of day and as explored through perceived visual comfort. The study's research 
question was as follows: How do day, evening, and night shift staff experience and use a circadian lighting installation in practice? We hypothesized that staff would choose the words "warm" and "naturalistic" most frequently to describe the light over the course of a day. Based on research demonstrating that lighting has a significant effect on residents with dementia, it was hypothesized that night shift staff in particular would experience an improved job satisfaction. The novelty of this study lies in its methodological approach and used card sorting, as a method to understand the respondent's perception of the lighting.

\section{Previous Research}

Occupants' experience of light and space (e.g., perceived visual comfort and light appraisal, user satisfaction, lighting control) has been studied extensively in daylight conditions and office environments $[4,7,15,19,22,27]$. These studies found that respondents who perceived the lighting in their office space as being of higher quality rated the setting as more attractive. Respondents who reported higher satisfaction with lighting were also happier and more satisfied with their work environment [27]. Satisfaction with work environments is connected to occupants' general well-being (e.g., fatigue levels, sleep quality), productivity, performance of tasks (e.g., frequency of errors), and efficiency, in which lighting plays an important role [5,9,10,21]. In addition, lighting systems designed to regulate the timing of circadian rhythms in humans and ensure exposure at the proper time of day have positive non-visual effects on sleep patterns, depression, anxiety, activity levels, and fatigue [12,14]; they also reduce restlessness and alertness and exert calming effects on elderly persons with dementia $[10,11,18,20,25]$.

Lighting systems that affect biological (non-visual), visual, and behavioral (psychological) responses are referred to by several terms. Among the most common are "human-centric lighting," "circadian lighting," "24-hour lighting scheme," and "integrative lighting" [17,26]. Due to its profound health-promoting effects on patients and staff with few documented side effects, circadian lighting has become increasingly popular in hospitals and elder care facilities as a welfare technology and nonpharmacological treatment option $[12,29]$. However, field research studying visual comfort and user satisfaction in health care is limited [28]. The lack of research in this field could be due to the difficulty of studying lighting conditions in real-life situations in which it is challenging to isolate the variables and factors of effect [28]. Moreover, field research can be more costly and time consuming, and there can be difficulties related to access and ethical issues.

\section{Context and light settings}

The selection of the nursing home described in this paper was based on pragmatic grounds and criteria, such as availability (upcoming project), time (season), and physical access to the case and respondents. The Danish nursing home is located in Copenhagen and specializes in working with residents with dementia. There are 48 apartments divided among six houses (lettered A-F). Staff supervise the nursing home at all times. It is home to senior residents with various degrees of dementia, who depend on assistance from staff for daily activities such as eating, going to bed, and performing general hygiene tasks.

In 2018, Chroma Zenit (Chromaviso, Denmark) a 24-hour circadian lighting system was installed at this nursing home in the hallways, staff offices, shared bathrooms, kitchen unit, dining room, and television area. Besides the Chroma Zenit system, the common areas in the houses are illuminated by daylight entering from skylight windows and regular vertical windows. In addition, the circadian lighting was installed in four residential apartments at the same time.

The lighting consists of LED-based luminaires (consisting of individually controllable LEDs) that follow a dynamic lighting scheme with manual override options. Chroma Zenit is designed to regulate the timing of the circadian clock in elderly residents and staff members, and it has documented positive effects on, for example, sleep, fatigue, depression, delirious behavior, and nocturnal disruptions [29].

The Chroma Zenit lighting system operates automatically and follows a predefined scheme with sunrise at 07:00 and sunset at 22:00 (starting and ending at 1800K). During the morning, the light brightens continuously in intensity and CCT (correlated color temperature) until it peaks around noon. From 14:00, it dims in intensity and CCT during the afternoon until nighttime. From 22:00, the lighting remains static throughout the night until it resets in the morning.

At night, the light spectrum contains less than $1 \%$ of the energy below $520 \mathrm{~nm}$, which is mainly the blue wavelength domain. As a result, the light is perceived as amber. The nighttime light spectrum is designed this way to avoid disturbing the production of melatonin by anyone awake during that period. It is designed to be perceived as comfortable for night shift staff to work in.

Besides the cyclical lighting scheme, staff can choose a set of lighting scenarios in the common areas and the television room. These lighting scenarios are installed to enable the staff to change the lighting to support various activities such as social events arranged by staff or television viewing. In the common dining area and television room, the lighting is operated using a panel engraved with icons that symbolize the scenarios. The lighting scenarios included circadian lighting, full light, activity, cozy, and off. In addition, the lighting was dimmable (indicated by plus and minus symbols). The lighting in the hallway and in the apartments was controlled using switches without icons to hide them from the elderly residents.

\section{Methodology}

This study applied an action research approach [3] to lighting. This means that we aimed to produce knowledge that can be used in practice (e.g., knowledge that can be used evaluate lighting installations with the aim of improving lighting conditions and work environments for occupants). The action research was conducted from September 2020 to January 2021. 


\subsection{Participants and ethics}

The participants consisted of 42 staff members ( 35 women, 6 men, and 1 other) out of 51 employed by the nursing home. Of the 42 staff members, 26 had more than three years of experience, and 32 were employed as social and health care assistants. In total, 21 staff members worked on day shifts, whereas 18 worked evening shifts, and 4 worked night shifts. The staff had fixed working schedules. Twenty-five participants reported using glasses or contact lenses. The staff who were included in the study were Danish speaking full-time and part-time employees who had worked at the nursing home for more than 2 months at the time of inclusion. Excluded from the study were hourly employees and participants who worked fewer than $80 \%$ of their shifts at the nursing home. Participants with known eye diseases were also excluded.

We followed the Standards for Reporting Qualitative Research (SRQR) [24]. Prior to participation, all participants completed an informed consent form that included the right to withdraw at any time, the right to refuse to answer the questions, and a guarantee of the participants' anonymity. All participants were provided with anonymized ID numbers. The participants' personal information was kept encrypted in a database that was separated from the other information used in the study. We applied special ethical considerations for access, permission, and data handling within the health care sector. This study received ethical approval (ID2021020-00540) by an ethics committee at Aalborg University.

\subsection{Materials and Procedure}

A mixed method approach was used consisting of interviews $(\mathrm{n}=10)$, go-along observations $(\mathrm{n}=5)$, and a questionnaire $(\mathrm{n}=42)$.

Ten staff members were recruited for interviews, which had a duration of approximately 45 minutes. These were conducted in a meeting space equipped with the circadian lighting system. The interviews were recorded using a Dictaphone [Olympus LS-P1] and stored on a secure server. During the interview, two probes were introduced. First, a card sorting exercise was performed to facilitate mutual communication about lighting and visual comfort and to gain insight into how the staff perceived the lighting. Twelve laminated cards were designed with an equal number of positive and negative words. The words described different lighting attributes, and the choice of words was inspired by $[13,26]$. The participants were asked to select the cards they thought best described the current lighting in their workspace. They were instructed to pick as many of the cards as they wanted. Once they had chosen the cards, the participants were asked to place them in front of themselves on the table. Thereafter, the interviewer asked why they had chosen the specific cards and which cards they would select if it were another time of day, such as evening compared to early afternoon. The cards' arrangement was photographed and labeled with an ID number. The cards as shuffled between each interview.

Five go-along observations were collected during the period of study: one morning observation, two evening observations, and two-night observations. It was agreed beforehand based on convenience whom the researcher should shadow while working.
The focus of the observations was to capture the interactions and use of light. The observer focused on the events that occurred and did not note any personal information about the residents. One observation was collected prior to the first interview to inform the interview guide. The observer was careful to avoid being intrusive in the work and maintained a passive level of involvement [3]. Questionnaires in printed format was distributed on January 26, 2021. The questionnaire was distributed after a sales representative of Chromaviso held a follow-up introduction about the lighting application. The questionnaire was inspired by prior questionnaires on visual comfort and satisfaction (i.e., $[1,28]$ ) and included the following topics: implementation, usefulness, usability, and experience of the lighting. The questionnaire consisted of 30 items and a used five-point Likert scale.

\subsection{Data analysis}

The questionnaires were analyzed using cumulative frequency. The interviews were analyzed using traditional coding [3] via the following four steps: organizing, recognizing, coding, and interpretation. The interviews were transcribed verbatim to be organized and prepared for data analysis. The transcripts were read several times by two researchers to recognize the concepts and themes, which also included a general sense of the information and an opportunity to reflect on its overall meaning. The researchers then coded and labeled the data in categories and subcategories using Nvivo12, followed by interpretation.

\section{Findings}

\subsection{Light practice}

Staff members were asked how often they use the circadian lighting settings. Eighteen participants replied "weekly", 15 replied "daily", 6 replied "monthly", 2 replied "rarely", and none replied "never". In the apartments with the circadian lighting, the researcher observed how staff changed the lighting during wake-up time. While performing his work, a staff member explained that when he wakes up elderly persons, he sets the soft lighting on to gently indicate that it is time to wake up. Thereafter, however, he switches it to a brighter light to indicate that it is time to get up and to ensure that he can see what he is doing.

In addition, almost all staff members perceived it as very important to be able to adjust the circadian lighting (Q2.5, Table 2). The importance of adjusting the circadian lighting was also evident in the staff members' expression of changing the lighting to different activities:

"I adjust it [the light] so I can see the resident. As I explained, it is important to have some light here so I can see if there is something wrong with the resident. To be able to see them is probably important to me, so I know if there is something I need to react to, or that I might have missed if the light wasn't turned on. In this way, it is very important for me to see the resident. Umm...also, when I need to help the resident to the toilet, so to speak, the 
lighting gives them some extra security, which also helps them to see properly." (ID 5, night shift)

On one hand, being able to have proper lighting for performing work assignments, providing care, and having visibility for inspecting residents was important to the staff. On the other hand, the ability to adjust the illuminance and CCT according to the desired atmosphere during activities such as watching television in the living room, doing creative tasks at the tables, or participating in seasonal activities was also important. This was especially articulated by evening staff:

"Because you could say that it is this time [evening] when, until they [the residents] need to go to bed, they are seated in the living or dining area. It becomes homely when we can dim the lights and set some cozy lights." (ID 9, evening shift).

\subsection{Lighting Assessment}

The words chosen most often to describe the circadian lighting were "naturalistic," "warm," and "bright". Each was chosen five times during the card-sorting exercise (Figure 1). The second most chosen term was the word "soft," which was selected by four respondents.

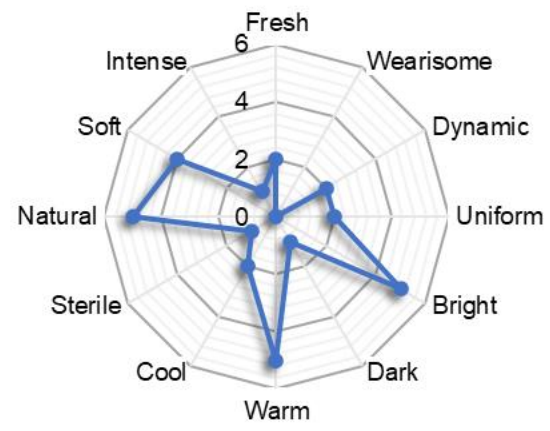

Figure 1: Distribution of selected words chosen during cardsorting exercise (accumulated from 11 interviews).

The word "naturalistic" related to diurnal changes in illuminance and correlated color temperature. As expected, "warm" was used in relation to "soft" to explain the lighting during the early morning hours, late evening, and night. For instance, a night shift worker referred to visual comfort while explaining her choice of "warm" as follows:

"I think it is warm because it [the lighting] changes to a warmer yellow color, not that white, sharp one. Thus, I also find it soft, like, you know, for the eyes. You don't get discomfort in your eyes by looking at it, and it is pleasant to be in." (ID 4, night shift)

These choices were also evident in the questionnaire, in which 22 of 40 respondents rated the lighting as natural (Q1, Table 1, $\mathrm{SD}=1.53 ; \mathrm{M}=2.35$ ). In addition, independent of shift type, the staff seemed to agree that the lighting was not artificial $(17=$ no extent and $13=$ low extent, Table 1 ), and only one staff member perceived the lighting as sterile (Table 1).

\begin{tabular}{|c|c|c|c|c|c|c|c|c|}
\hline $\begin{array}{l}1=\text { No extent. } 2=\text { low } \\
\text { extent. } 3=\text { Neutral. } 4= \\
\text { Moderate extent } 5= \\
\text { Greater extent }\end{array}$ & 1 & 2 & 3 & 4 & 5 & Total & Mean & SD \\
\hline 1. The lighting is natural & 2 & 4 & 6 & 22 & 6 & 40 & 2.35 & 1.53 \\
\hline 2. The lighting is artificial & 17 & 13 & 7 & 2 & 3 & 42 & 3.93 & 1.98 \\
\hline 3. The lighting is invigorating & 2 & 8 & 13 & 9 & 7 & 39 & 2.72 & 1.65 \\
\hline 4. The lighting is boring & 23 & 8 & 5 & 2 & 3 & 41 & 4.12 & 2.03 \\
\hline 5. The lighting is warm & 8 & 4 & 8 & 11 & 4 & 35 & 3.03 & 1.74 \\
\hline 6. The lighting is cold & 22 & 3 & 6 & 4 & 1 & 36 & 4.14 & 2.03 \\
\hline 7. The lighting is powerful & 12 & 6 & 13 & 5 & 2 & 38 & 3.55 & 1.88 \\
\hline 8. The lighting is weak & 19 & 4 & 8 & 3 & 1 & 35 & 4.06 & 2.01 \\
\hline
\end{tabular}

Table 1: Distribution of selected words chosen during cardsorting exercise (accumulated from 11 interviews).

The lighting was not perceived as wearisome or boring. However, when asked about the color temperature (e.g., cold, or warm) in the questionnaire (Table 1), the respondents exhibited no clear tendency in their answers. For warm color temperatures, a broad dispersion in answers was evident (SD 1.74; M=3.03)(Q5, Table 1). This might have occurred because the staff members work at different times of day. Negative words such as "wearisome," "sterile," "dark," and "uniform" were chosen only $0,1,1$, and 2 times, respectively. However, the interviews revealed that the words could have a double meaning. For example, the interviews showed that the respondents used the word "bright" both positively and negatively. They connected brightness to visibility and being able to perform tasks. One respondent, when asked in the interview whether she used the word negatively or positively, stated,

"No, I think it is good. It is bright - that is, you can see what you write on the computer or on a piece of paper." (ID 8, evening shift)

However, "bright" was also used negatively. ID10 connected it to seasonal changes:

"At this time of season, for example, it does not match the darkness of the season, and I think it glares. I think it is too bright. It is difficult to make certain spaces cozy, like in the television room in the evening." (ID10, evening shift)

Furthermore, three out of four interviewed evening staff members expressed a dissonance between the time when the lighting starts to dim and transit from evening to night light and the time when the residents go to bed. They all expressed a need for the lighting to dim at the beginning of the evening. As ID10 stated, "They have not experienced when it dims, and especially not at this time of year, where the light dims right or becomes darker." Here, ID 10 refers to the shortening of the daylight minutes during the winter. 


\subsection{Light Satisfaction}

The staff expressed high satisfaction with the lighting at their workplace (Q 2.1-Q2.6) Q2.1: $\mathrm{SD}=2.01 ; \mathrm{M}=4.05$ (Table 2).

\begin{tabular}{|c|c|c|c|c|c|c|c|c|}
\hline $\begin{array}{l}1=\text { Strongly Disagree. } 2 \text { = Disagree. } 3 \text { = Neither or disagree. } 4 \\
\text { = Agree. } 5 \text { = Strongly agree }\end{array}$ & 1 & 2 & 3 & 4 & & Total & IMean & SD \\
\hline \multicolumn{9}{|l|}{ 1. Before/ After the introduction } \\
\hline $\begin{array}{l}\text { Q1.1: Before the introduction I knew how the circadian } \\
\text { lighting works }\end{array}$ & 3 & 4 & 7 & 15 & 11 & 40 & 3.68 & 1.92 \\
\hline $\begin{array}{l}\text { Q1.2: After the introduction I know how the circadian lighting } \\
\text { works }\end{array}$ & 1 & 0 & 5 & 16 & 19 & 41 & 4.27 & 2.07 \\
\hline $\begin{array}{l}\text { Q1.3: It makes sense for me when and where the circadian } \\
\text { lighting can be used }\end{array}$ & 0 & 2 & 6 & 18 & 15 & 41 & 4.12 & 2.03 \\
\hline \multicolumn{9}{|l|}{ 2. Workplace } \\
\hline $\begin{array}{l}\text { Q2.1: In general, I am satisfied with the circadian lighting at } \\
\text { my workplace }\end{array}$ & 2 & 2 & 4 & 17 & 16 & 41 & 4.05 & 2.01 \\
\hline $\begin{array}{l}\text { Q2.2: I perceive values in the circadian lighting for both me } \\
\text { and the residents }\end{array}$ & 1 & 2 & 3 & 17 & 19 & 42 & 4.21 & 2.05 \\
\hline Q2.3: The circadian lighting is easy to use & 0 & 1 & 5 & 21 & 15 & 42 & 4.19 & 2.05 \\
\hline Q2.4: It is comfortable to be and work in the circadian I & 0 & 0 & 6 & 22 & 14 & 42 & 4.19 & 2.05 \\
\hline $\begin{array}{l}\text { Q2.5: It is important that the circadian lighting is adjustable } \\
\text { according to different work situations }\end{array}$ & 0 & 1 & 7 & 18 & 16 & 42 & 4.17 & 2.04 \\
\hline $\begin{array}{l}\text { 22.6: I perceive the circadian lighting as a normal part in my } \\
\text { everyday work }\end{array}$ & 1 & 1 & 4 & 23 & 13 & 42 & 4.10 & 2.02 \\
\hline \multicolumn{9}{|l|}{ 3. Perceived circadian lighting experiences } \\
\hline Q3.1: I can read, write, and perform tasks in the current lig & 2 & 0 & 4 & 27 & 9 & 42 & 3.98 & 1.99 \\
\hline Q3.2 & 3 & 1 & 4 & 26 & 8 & 42 & 3.83 & 1.96 \\
\hline $\begin{array}{l}\text { Q3.3: I often experience that the lighting does not work as it } \\
\text { should }\end{array}$ & 1 & 10 & 5 & 14 & 12 & 42 & 3.62 & 1.90 \\
\hline \multicolumn{9}{|l|}{ 4. Well-being } \\
\hline Q4.1: I feel sleepy a & 9 & 16 & 10 & 3 & 4 & 42 & 2.45 & 1.57 \\
\hline 4.2: I have difficulties being concentrated $c$ & 12 & 22 & 3 & 1 & 4 & 42 & 2.12 & 1.46 \\
\hline 24.3: I have & 12 & 19 & 5 & 2 & 4 & 42 & 2.21 & 1.49 \\
\hline from work & 0 & 4 & 5 & 6 & 7 & 22 & 3.73 & 1.93 \\
\hline
\end{tabular}

Table 2: Cumulative frequency of answers from questionnaire $(n=42)$.

Twenty-two participants agreed that the lighting was comfortable to work in, and 19 strongly agreed when asked whether they perceived the circadian lighting to be valuable for them and the residents living at the nursing home (Q2.2, Table 2). The new lighting system was perceived as easy to use (Q2.3, Table 2). However, younger staff found it a little easier to use the circadian lighting than the older staff members did. Similarly, younger staff members perceived slightly more value in the circadian lighting than older staff members did. Moreover, the staff perceived the circadian lighting to be a normal part of their everyday work (Q2.6, Table 2), $\mathrm{SD}=2.02, \mathrm{M}=4.10$. The staff also appraised the circadian lighting clearly in the interviews. For instance, they expressed higher satisfaction with the circadian lighting compared to the dimmable white lighting installed in the residents' apartments:

"It is much better than the light they have in their apartments [...] the lamps on the walls, and the like. They are not really good for working, not for cases where you need to inspect a wound or something else up close.” (ID 10, evening shift)

As exemplified in this statement, the evening staff's satisfaction was linked to the visibility the lighting provided. They also expressed their satisfaction when asked to describe the lighting that was installed prior to the circadian lighting.
"It was more, like, powerful [referring to the old light]. You know, I have never had issues with light, and never had a headache, though after the new [light] arrived that, like, could change color, I thought it was terrific for the eyes also. The other [light] was really such a white, much sharper light, you know.” (ID 4, night shift)

\subsection{Workload}

Satisfaction with the lighting was also visible in the workload described by the staff, as the lighting has an indirect effect on the residents' nocturnal activity. Four night staff and two evening staff articulated their observations on nocturnal activity. Two members (ID 8 and ID 5) explained how the circadian lighting, compared to the past lighting system, does not invite the residents to wander away from their apartments:

"It is clear that if somebody wakes up and looks outside, then it is of course bright, and this might invite to them to walk out. Today, when some of our residents look out, then it is dark, and they might think, 'Huh, it is dark,' then turn around and walk back inside." (ID 8 , evening shift)

All four staff who were permanent night shift workers stated they had experienced a significant reduction in nocturnal activity compared to before circadian lighting was installed:

"We experienced, prior to circadian lighting, a lot of nocturnal activities among the citizens, but after circadian lighting was installed, it steadily decreased." (ID 5, night shift)

\section{Conclusion}

The present study set out to investigate staff's perception and experience of working in a 24-hour lighting schedule installed in a Danish nursing home. The study concludes that staff expressed high satisfaction with the circadian lighting in their workspace, and as being comfortable to work in. However, the younger staff perceived slightly more value in circadian lighting than older staff members did. Furthermore, the study reveals that younger staff perceived the circadian lighting a little easier to use compared to the older members. Although this study does not document the effects of circadian lighting on residents, the staff's perceived improvement in the residents' sleeping patterns indicate a potential positive spillover effects on the staff's well-being and job satisfaction. The interviews showed how card-sorting, as a method to understand the respondent's perception of the lighting, can be valuable to uncover similarities and diversities in end-user experience of the lighting. These are experiences that otherwise would be difficult to capture in a laboratory setting. However, this method is not a stand-alone instrument, and should be supported by other methods, as demonstrated in this paper. In this study, we find the structured qualitative card sorting is a valuable method for encouraging participants to talk about the rather abstract topic of the usefulness of a circadian lighting system within the context of their work comfort.

To establish robustness of our findings, future studies should provide further field-studies, of similar and different work environments such as hospitals with various end-users. This study 
includes both day, evening, and night-shift workers, as this provides a general idea of the experiences and needs of staff at different times of day. Previous literature has by large, studied night-shift workers, as they are at most risk of developing longterm illness, such as cardiovascular disease. In this study, our participants had fixed shifts, thus rotating shift schedules should be considered for future studies. Lastly, through an action research, this study has identified experiences that can be considered and applied in optimization and adjustment of circadian lighting design.

\section{ACKNOWLEDGMENTS}

The authors would like to thank all participants who accepted to participate in this study. We are grateful to Michael Mullins (Aalborg University) and Ane Søby Eskildsen (Chromaviso), who both helped us with valuable understandings and applied insights. Further, Ane Søby Eskildsen helped as coder within the intercoder reliability approach.

\section{REFERENCES}

[1] Alicia C. Allan, Veronica Garcia-Hansen, Gillian Isoardi, and Simon S Smith. 2019. Subjective Assessments of Lighting Quality: A Measurement Review. LEUKOS 15, 2-3 (July 2019), 115-126. DOI:https://doi.org/10.1080/15502724.2018.1531017

[2] Diane Applebaum, Susan Fowler, Nancy Fiedler, Omowunmi Osinubi, an Mark Robson. 2010. The Impact of Environmental Factors on Nursing Stress, Job Satisfaction, and Turnover Intention. J. Nurs. Adm. 40, 7-8 (2010), 323-328. DOI:https://doi.org/10.1097/NNA.0b013e3181e9393b

[3] Thomas Bjørner. 2015. Qualitative methods for Consumer Research (1st ed.). Hans Reizel.

[4] C Cajochen, M Freyburger, T Basishvili, C Garbazza, F Rudzik, C Renz, K Kobayashi, Y Shirakawa, O Stefani, and J Weibel. 2019. Effect of daylight LED on visual comfort, melatonin, mood, waking performance and sleep. Light. Res. Technol. 51, 7 (November 2019), 1044-1062. DOI:https://doi.org/10.1177/1477153519828419

[5] Yanjun Chen, Aimee Teo Broman, Geoffrey Priest, Christopher P. Landrigan, Shadab A. Rahman, and Steven W. Lockley. 2021. The Effect of Blue-Enriched Lighting on Medical Error Rate in a University Hospital ICU. Jt. Comm. J. Qual. Patient Saf. 47, 3 (2021), 165-175. DOI:https://doi.org/https://doi.org/10.1016/j.jcjq.2020.11.007

[6] Robert G. Davis, Lindsay J. McCunn, Andrea Wilkerson, and Sarah Safranek. 2020. Nurses' Satisfaction With Patient Room Lighting Conditions: A Study of Nurses in Four Hospitals With Differences in the Environment of Care. HERD 13, 3 (2020), 110-124. DOI:https://doi.org/http://dx.doi.org/10.1177/1937586719890940

[7] J. van Duijnhoven, M. P.J. Aarts, M. B.C. Aries, A. L.P. Rosemann, and H. S.M. Kort. 2019. Systematic review on the interaction between office light conditions and occupational health: Elucidating gaps and methodological issues. Indoor and Built Environment 28, 152-174. DOI:https://doi.org/10.1177/1420326X17735162

[8] Marie Engwall, Isabell Fridh, Lotta Johansson, Ingegerd Bergbom, and Berit Lindahl. 2015. Lighting, sleep and circadian rhythm: An intervention study in the intensive care unit. Intensive Crit. Care Nurs. 31, 6 (December 2015), 325-335. DOI:https://doi.org/10.1016/j.iccn.2015.07.001

[9] Mariana G. Figueiro, Robert Hamner, Patricia Higgins, Thomas Hornick, and Mark S. Rea. 2012. Field measurements of light exposures and circadian disruption in two populations of older adults. J. Alzheimer's Dis. 31, 4 (2012), 711-715. DOI:https://doi.org/10.3233/JAD-2012-120484

[10] Mariana G. Figueiro, Claudia M. Hunter, Patricia A. Higgins, Thomas R. Hornick, Geoffrey E. Jones, Barbara Plitnick, Jennifer Brons, and Mark S. Rea. 2015. Tailored lighting intervention for persons with dementia and caregivers living at home. Sleep Heal. 1, 4 (December 2015), 322-330. DOI:https://doi.org/10.1016/j.sleh.2015.09.003

[11] Mariana G. Figueiro, Barbara A. Plitnick, Anna Lok, Geoffrey E. Jones, Patricia Higgins, Thomas R. Rhornick, and Mark S. Rea. 2014. Tailored lighting intervention improves measures of sleep, depression, and agitation in persons with Alzheimer's disease and related dementia living in long- term care facilities. Clin. Interv. Aging 9, (2014), 1527-1537. DOI:https://doi.org/10.2147/CIA.S68557

[12] MG Figueiro, R Nagare, and LLA Price. 2018. Non-visual effects of light: How to use light to promote circadian entrainment and elicit alertness. Light. Res. Technol. 50, 1 (January 2018), 38-62. DOI:https://doi.org/10.1177/1477153517721598

[13] John E Flynn. 1977. A study of subjective responses to low energy and nonuniform lighting systems. Light. Des. Appl. February (1977), 6-15.

[14] John E. Griepentrog, Hanna E. Labiner, Scott R. Gunn, and Matthew R. Rosengart. 2018. Bright environmental light improves the sleepiness of nightshift ICU nurses. Crit. Care 22, 1 (December 2018), 295. DOI:https://doi.org/10.1186/s13054-018-2233-4

[15] Ellen Kathrine Hansen, Thomas Bjørner, Emmanouil Xylakis, and Mihke Pajuste. 2021. An experiment of double dynamic lighting in an office responding to sky and daylight: Perceived effects on comfort, atmosphere and work engagement. Indoor Built Environ. 0, 0 (2021), 1-20. DOI:https://doi.org/10.1177/1420326X21991198

[16] Yousef Al horr, Mohammed Arif, Martha Katafygiotou, Ahmed Mazroei, Amit Kaushik, and Esam Elsarrag. 2016. Impact of indoor environmental quality on occupant well-being and comfort: A review of the literature. Int J. Sustain. Built Environ. 5, 1 (June 2016), 1-11. DOI:https://doi.org/10.1016/J.IJSBE.2016.03.006

[17] K. W. Houser, P. R. Boyce, J. M. Zeitzer, and M. Herf. 2021. Humancentric lighting: Myth, magic or metaphor? Light. Res. Technol. 53, 2 (2021), 97-118. DOI:https://doi.org/10.1177/1477153520958448

[18] I. M. Iskra-Golec, A. Wazna, and L. Smith. 2012. Effects of blue-enriched light on the daily course of mood, sleepiness and light perception: A field experiment. Light. Res. Technol. 44, 4 (December 2012), 506-513. DOI:https://doi.org/10.1177/1477153512447528

[19] Y. de Kort and K. Smolders. 2010. Effects of dynamic lighting on office workers: First results of a field study with monthly alternating settings. Light. Res. Technol. 42, 3 (2010), 345-360. DOI:https://doi.org/10.1177/1477153510378150

[20] Ellen van Lieshout-van Dal, Liselore Snaphaan, and Inge Bongers. 2019 Biodynamic lighting effects on the sleep pattern of people with dementia. Build. Environ. 150, (March 2019), 245-253. DOI:https://doi.org/10.1016/J.BUILDENV.2019.01.010

[21] L J McCunn, S Safranek, A Wilkerson, and R G Davis. 2020. Lighting Control in Patient Rooms: Understanding Nurses' Perceptions of Hospital Lighting Using Qualitative Methods. HERD 14, 2 (2020), 204-218. DOI:https://doi.org/https://doi.org/10.1177/1937586720946669

[22] Guy Newsham, Jay Brand, Cara Donnelly, Jennifer Veitch, Myriam Aries, and Kate Charles. 2009. Linking indoor environment conditions to job satisfaction: A field study. Build. Res. Inf. 37, 2 (March 2009), 129-147. DOI:https://doi.org/10.1080/09613210802710298

[23] Rebecka Maria Norman and Ingeborg Strømseng Sjetne. 2017. Measuring nurses' perception of work environment: A scoping review of questionnaires. BMC Nurs. 16, 1 (November 2017). DOI:https://doi.org/10.1186/s12912-017-0256-9

[24] Bridget C O'Brien, Ilene B Harris, Thomas J Beckman, Darcy A Reed, and David A Cook. 2014. Standards for Reporting Qualitative Research: A Synthesis of Recommendations. Acad. Med. 89, 9 (2014), 1245-1251. DOI:https://doi.org/10.1097/ACM.0000000000000388

[25] Birgit Sander, Jakob Markvart, Line Kessel, Aikaterini Argyraki, and Kjeld Johnsen. 2015. Can sleep quality and wellbeing be improved by changing the indoor lighting in the homes of healthy, elderly citizens? Chronobiol. Int $\quad 32, \quad 8$ (September 2015), 1049-1060. DOI:https://doi.org/10.3109/07420528.2015.1056304

[26] M. Stokkermans, I. Vogels, Y. de Kort, and I. Heynderickx. 2018. Relation between the perceived atmosphere of a lit environment and perceptual attributes of light. Light. Res. Technol. 50, 8 (December 2018), 1164-1178. DOI:https://doi.org/10.1177/1477153517722384

[27] J. A. Veitch, G. R. Newsham, P. R. Boyce, and C. C. Jones. 2008. Lighting appraisal, well-being and performance in open-plan offices: A linked mechanisms approach. Light. Res- Technol 40, 133-151 (2008). DOI:https://doi.org/10.1177/1477153507086279

[28] Valerio R M Lo Verso, Federica Caffaro, and Chiara Aghemo. 2016 Luminous environment in healthcare buildings for user satisfaction and comfort: an objective and subjective field study. Indoor Built Environ. 25, 5 (2016). DOI:https://doi.org/10.1177/1420326X15588337

[29] Anders West, Sofie Amalie Simonsen, Alexander Zielinski, Niklas Cyril, Marie Schønsted, Poul Jennum, Birgit Sander, and Helle K. Iversen. 2019. An exploratory investigation of the effect of naturalistic light on depression, anxiety, and cognitive outcomes in stroke patients during admission for rehabilitation: A randomized controlled trial. NeuroRehabilitation $\quad 44, \quad 3 \quad$ (2019), 341-351. DOI:https://doi.org/10.3233/NRE-182565 